\title{
触 New Disease Reports \\ First report of Tomato apical stunt viroid and Chrysanthemum stunt viroid in Solanum jasminoides in Austria
}

\author{
S. Grausgruber-Gröger* and R.A. Gottsberger
}

Austrian Agency for Health and Food Safety (AGES), Institute for Plant Health, Spargelfeldstrasse 191, A-1220 Vienna, Austria

*E-mail: sabine.grausgruber-groeger@ages.at

Received: 10 Mar 2011. Published: 24 Aug 2011.

To date Potato spindle tuber viroid (PSTVd) is the only solanaceous pospiviroid which is a regulated pest throughout the European Union. PSTVd has been detected consistently in ornamentals and occasionally in tomatoes (Solanum lycopersicum) in Austria during official surveys. Since 2009, tests for other pospiviroids have been done in Austria. During these surveys, Citrus exocortis viroid (CEVd) was detected in S. jasminoides (Gottsberger \& Suárez-Mahecha, 2010), and Chrysanthemum stunt viroid (CSVd) was found occasionally in chrysanthemum (Dendranthema $x$ grandiflorum).

During the PSTVd survey in 2010, leaves and shoots from different vegetable and ornamental crops produced and traded in Austria were tested. The samples were tested by reverse transcription RT-PCR using the primer pairs Pospi1-RE/FW and Vid-RE/FW (Verhoeven et al., 2004). Two pooled samples, each consisting of 200 shoots of $S$. jasminoides, were collected from nurseries in the provinces of Styria and Upper Austria. Both samples produced an amplification product using primer pair Pospi1-RE/FW; no product could be obtained with the Vid-RE/FW primers. Subsequently these samples were tested with the primer pairs for CEVd (Önelge, 1997) and CSVd (Hooftman et al., 1996). The Styrian sample generated an amplification product with the CSVd primer pair. Sequencing of the product yielded a sequence of 354 bp with $99 \%$ identity to the sequence of CSVd (GenBank Accession No. DQ406591). In two positions (bp 130 and bp 235) mismatches were observed and the sequence variant was submitted to GenBank (JF414238).

RT-PCR with the primer pairs for CEVd and CSVd produced amplification products with the sample from Upper Austria. Sequencing the CEVd product resulted in a 364 bp sequence (GenBank Accession No. JF927790) with $100 \%$ identity to Tomato apical stunt viroid (TASVd; FN994891). Plant sap from the TASVd-positive sample was used to inoculate mechanically eight tomato plants (cv. Zuckertraube) in the greenhouse. Five weeks after inoculation three plants had clear stunting symptoms (Fig. 1), three plants displayed small curled leaves (Fig. 2) and two plants did not show any symptoms. RT-PCR and sequencing of the tomato plant samples confirmed the presence of TASVd, the presence of CEVd and no infection, respectively. It was concluded that the Upper Austrian sample was co-infected with TASVd and CEVd and that the CEVd concentration was much lower than the TASVd concentration in the original sample. Therefore only TASVd could be detected in the original sample.

The Styrian CSVd-infected plants were grown in a nursery and had been imported as plantlets from two different German companies. The sample from Upper Austria derived from a consignment consisting of 3,000 S. jasminoides plantlets imported from Romania. Almost all plants had been

sold by the time the pospiviroid detection was confirmed. It is presumed that CSVd and TASVd are still present in Austria and that the infected plants could serve as source for further infections. The risk of symptomless but pospiviroid-infected ornamental plants acting as inoculum for crop plants has been discussed (Verhoeven et al., 2008, Gottsberger \& Suárez-Mahecha ,2010, Verhoeven et al., 2010). This is the first record of TASVd in Austria. CSVd has been found occasionally in chrysanthemum in Austria but this is the first report in S. jasminoides.

\section{References}

Gottsberger RA, Suárez-Mahecha B, 2010. Detection of Citrus exocortis viroid on Solanum jasminoides plantlets from an Austrian nursery. Plant Pathology 59,1159. [doi:10.1111/j.1365-3059.2010.02296.x]

Hooftman R, Arts MJ, Shamloul AM, Van Zaayen A, Hadidi A, 1996. Detection of Chrysanthemum stunt viroid by reverse transcription-polymerase chain reaction and by tissue blot hybridization. Acta Horticulturae 432, 88-94.

Önelge N, 1997. Direct nucleotide sequencing of Citrus exocortis viroid (CEV). Turkish Journal of Agriculture and Forestry 21, 419-422.

Verhoeven JThJ, Jansen CCC, Willemen TM, Kox LFF, Owens RA, Roenhorst JW, 2004. Natural infections of tomato by Citrus exocortis viroid, Columnea latent viroid, Potato spindle tuber viroid and Tomato chlorotic dwarf viroid. European Journal of Plant Pathology 110, 823-831. [doi:10.1007/s10658-004-2493-5]

Verhoeven JThJ, Jansen CCC, Roenhorst JW, 2008. First report of pospiviroids infecting ornamentals in the Netherlands: Citrus exocortis viroid in Verbena sp., Potato spindle tuber viroid in Brugmansia suaveolens and Solanum jasminoides, and Tomato apical stunt viroid in Cestrum sp. Plant Pathology 57, 399.

[doi:10.1111/j.1365-3059.2007.01662.x]

Verhoeven JThJ, Jansen CCC, Botermans M, Roenhorst JW, 2010. Epidemiological evidence that vegetatively propagated, solanaceous plant species act as sources of Potato spindle tuber viroid inoculum for tomato. Plant Pathology 59, 3-12. [doi:10.1111/j.1365-3059.2009.02173.x]

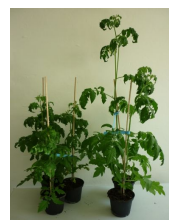

Figure 1

Figure 2

To cite this report: Grausgruber-Gröger S, Gottsberger RA, 2011. First report of Tomato apical stunt viroid and Chrysanthemum stunt viroid in Solanum jasminoides in Austria. New Disease Reports 24, 4. [doi:10.5197/j.2044-0588.2011.024.004]

(c)2011 The Authors

This report was published on-line at www.ndrs.org.uk where high quality versions of the figures can be found. 